\title{
ANÁLISE DO TEOR DE ETANOL NA GASOLINA COMERCIALIZADA NOS POSTOS DE COMBUSTÍVEIS DO MUNICÍPIO DE GUARAÍ-TO
}

\author{
ANALYSIS OF THE ETHANOL CONTENT IN GASOLINE COMMERCIALIZED IN \\ FUEL STATIONS IN THE MUNICIPALITY OF GUARAÍ-TO \\ ANÁLISIS DEL CONTENIDO DE ETANOL EN GASOLINA COMERCIALIZADA EN \\ ESTACIONES DE COMBUSTIBLE EN EL MUNICIPIO DE GUARAÍ-TO
}

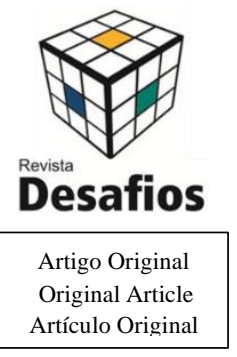

\section{Matheus Victor de Moura Nascimento ${ }^{1}$, Gustavo Oliveira Silva ${ }^{1}$, Anderson José Gonzaga Lemos ${ }^{* 2}$}

${ }^{1}$ Acadêmico do Curso de Graduação em Biomedicina, Instituto Educacional Santa Catarina (IESC), Guaraí - TO, Brasil.

${ }^{2}$ Professor do Instituto Educacional Santa Catarina, Guaraí - TO, Brasil.

*Correspondência: Laboratório de Química e Bioquímica, Instituto Educacional Santa Catarina, Av. JK, 2541, Setor Universitário, Guaraí,Tocantins, Brasil.CEP:77.700-000.e-mail Anderson.lemos@iescfag.edu.br.

\section{RESUMO}

A gasolina é um produto derivado do petróleo constituído quimicamente por uma mistura complexa de hidrocarbonetos, sendo um dos principais combustíveis utilizados por veículos automotores. Por este motivo, é de grande importância que sua qualidade seja avaliada e assegurada. Por meio de uma resolução do Conselho Interministerial do Açúcar e do Álcool (CIMA), foi estabelecido como aceitável um teor de etanol em gasolina de no máximo $27 \%$ em volume. Dessa maneira, percentuais que excedam o valor exposto caracteriza o combustível como adulterado. Com base nisso, foi realizada a análise de amostras de gasolina comum comercializada no município de Guaraí - TO. Realizou-se análise físico-química em amostras de gasolina e verificou-se que os mesmos apresentavam teores de etanol entre 21 a $25 \%$, encontrando-se dentro das especificações determinadas pela legislação brasileira.

Palavras-chave: Gasolina; Etanol; Análise físico - química.

\section{ABSTRACT}

Gasoline is a petroleum product chemically constituted by a complex mixture of hydrocarbons, being one of the main fuels used by motor vehicles. In this way, it is of great importance that its quality be evaluated and ensured. Through a resolution of the Conselho Interministerial do Açúcar e do Álcool (CIMA), an acceptable content of ethanol contained in gasoline was established as $27 \%$. In this way, percentages that exceed the exposed value characterize the fuel as adulterated. Based on this, the analysis of samples of common gasoline marketed in the municipality of Guarai - TO. was carried out Physical-chemical analysis was carried out on gasoline samples, where it was found that they had ethanol content between 21 and 25\%, being within the specifications of the current law.

Keywords: Gasoline; Ethanol; Chemical physical - analysis.

\section{RESUMEN}

La gasolina es un producto derivado del petróleo constituido químicamente por una mezcla compleja de hidrocarburos, siendo uno de los principales combustibles utilizados por vehículos automotores. Por este motivo, es de gran importancia que su calidad sea evaluada y asegurada. Por medio de una resolución del Consejo Interministerial del Azúcar y del Alcohol (CIMA), se estableció aceptable un contenido de etanol en gasolina como del 27\%. De esta manera, porcentuales que excedan el valor expuesto caracterizan el combustible como adulterado. Con base en ello, se realizó el análisis de muestras de gasolina común comercializada en el municipio de Guaraí - 
TO. Se realizó análisis físico-químico en muestras de gasolina y se constató que los mismos presentan un contenido de etanol entre 21 a 25\%, encontrándose dentro de las especificaciones determinadas por la legislación.

Descriptores: Gasolina; Etanol; Análisis físico - químico.

\section{INTRODUÇÃO}

A utilização do petróleo como fonte de energia está entre os grandes fatores responsáveis pelo desenvolvimento industrial ocorridos no século passado (AMPARADO et al., 2016). Através da destilação fracionada do petróleo pode-se dar origem a vários produtos, sendo a gasolina um dos mais importantes economicamente (LODICE et al., 2016; AMPARADO et al., 2016; DAHL, 2012). Devido sua enorme importância no setor automobilístico bem como sua considerável oscilação de preço no mercado, a qualidade da gasolina comercializada no Brasil sempre é motivo de questionamentos (ANP, 2018; AMPARADO et al., 2016). Nas últimas décadas, a prática de adulteração em combustíveis tem gerado preocupação nos órgãos fiscalizadores e tem levado a Agência Nacional do petróleo, Gás Natural e Biocombustíveis (ANP), a impor medidas para coibir essa ação ilícita nos postos de combustíveis em todo o país. Por meio de uma Resolução do Conselho Interministerial do Açúcar e do Álcool (CIMA) de 4 de março de 2015, foi estabelecido como aceitável um teor de etanol em gasolina de no máximo $27 \%$ em volume, conforme disposto no Art. $1^{\circ}$, da Lei 10.203/2001 (ANP, 2017). A utilização de gasolina adulterada com etanol (álcool anidro) pode provocar danos funcionais em motores e aumentar consideravelmente o consumo de combustível, bem como provocar corrosão de componentes metálicos (CARVALHO e DANTAS, 2014; MASUN et al., 2013; NIVEN, 2005). Além disso, o uso de gasolina adulterada também causa impactos ambientais, uma vez que aumenta a produção de poluentes como óxidos de nitrogênio (NOx) e óxidos de enxofre (SOx), bem como monóxido de carbono (CO), que também está vinculado com o desencadeamento de doenças (MENDES e BARBEIRA, 2013; NIVEN, 2005). Como percentuais de etanol em gasolina superiores a $27 \%$ caracterizam adulteração, o objetivo deste trabalho foi quantificar os teores de etanol em amostras de gasolina comum, obtidas a partir dos postos de combustíveis do município de Guaraí - TO, com o intuito de avaliar se os mesmos estão de acordo com as normas estabelecidas por lei.

\section{MATERIAIS E MÉTODOS}

Inicialmente, preparou-se uma solução aquosa de $\mathrm{NaCl}$ com concentração de $10 \%$. Em seguida, adicionou-se $50 \mathrm{~mL}$ de gasolina e $50 \mathrm{~mL}$ da solução aquosa de $\mathrm{NaCl}$ em uma proveta. Após constituição das fases, e com a proveta hermeticamente fechada, agitou-se a mistura a fim de intensificar o deslocamento do etanol para o sentido aquoso. Uma solução iônica apresenta maior polaridade que água pura, favorecendo o deslocamento do etanol entre as fases. Transcorridos 15 minutos, verificou-se o aumentou de volume na solução salina. Para calcular o percentual de etanol nas amostras foi utilizada a seguinte equação:

$\mathrm{PA}=[(\mathrm{A}-50) \mathrm{X} 2]+1$

Onde PA é o percentual de etanol, determinado pela diferença entre volume inicial (50) e volume final (A), multiplicado por dois e somado a um (ABNT, 1997). As amostras de gasolina para análise foram recolhidas nos três postos de combustíveis em funcionamento na cidade de Guaraí - TO e nomeados aleatoriamente como "X", "Y" e "Z". 


\section{RESULTADOS E DISCUSSÃO}

O experimento foi realizado através de uma extração líquido-líquido, que se baseia na diferença de solubilidade existentes entre etanol e gasolina na presença de uma solução iônica de $\mathrm{NaCl}$. Devido o fato da molécula de etanol possuir propriedades anfipáticas, isto é, apresentar fração polar e apolar, sua porção apolar possui afinidade pelas moléculas apolares da gasolina, ao passo que sua fração polar, caracterizada pela presença do grupo hidroxila $(\mathrm{OH})$, tende a se deslocar no sentido da fase aquosa, também polar, vindo a interagir com esta solução através do estabelecimento de pontes de hidrogênio. Dessa maneira, uma vez que estabelecido um sistema heterogêneo bifásico entre gasolina e uma solução aquosa de $\mathrm{NaCl}$, o deslocamento do etanol para a solução iônica determina um aumento de volume que permite determinar quase que invariavelmente, os teores de etanol contido na gasolina analisada. Com os resultados obtidos nas análises físico-químicas entre as três amostras analisadas, todos os postos foram considerados dentro dos critérios estabelecidos pela ANP. Na Tabela 1 são apresentadas as diferenças de volumes comparados aos valores iniciais e finais das amostras, e seus respectivos valores percentuais.

Tabela 1. Porcentagem de etanol presente nas amostras de gasolina analisadas.

\begin{tabular}{|c|c|c|c|}
\hline $\begin{array}{c}\text { Posto de } \\
\text { Combustível }\end{array}$ & $\begin{array}{c}\text { Volume } \\
\text { Inicial } \\
(\mathbf{m L})\end{array}$ & $\begin{array}{c}\text { Volume } \\
\text { Final } \\
(\mathbf{m L})\end{array}$ & $\begin{array}{c}\text { Teor } \\
\text { Determinado } \\
(\mathbf{\%})\end{array}$ \\
\hline $\mathrm{X}$ & 50 & 62 & 25 \\
\hline $\mathrm{Y}$ & 50 & 60 & 21 \\
\hline $\mathrm{Z}$ & 50 & 61 & 23 \\
\hline
\end{tabular}

\section{CONCLUSÃO}

Foi demonstrado através deste experimento que todas as amostras de gasolina analisadas apresentavam teor de etanol inferior a $27 \%$. Desta maneira, todos os postos avaliados estão comercializando gasolina de acordo com as especificações estabelecidas por lei. Além disso, o método utilizado se mostrou eficiente para a análise, demonstrando a grande aplicabilidade de métodos físico-químicos para a realização de pesquisas.

\section{AGRADECIMENTO}

Este artigo é resultado das atividades de iniciação científica desenvolvidas no curso de bacharelado em Biomedicina do Instituto Educacional Santa Catarina.

Todos os autores declararam não haver qualquer potencial conflito de interesses referente a este artigo.

\section{REFERÊNCIAS}

ANP - AGÊNCIA NACIONAL DO PETRÓLEO, GÁS NATURAL E BIOCOMBUSTÍVEIS. Disponível em: http://www.anp.gov.br/wwwanp. Acesso em: 01 agosto de 2018.

AMPARADO, B. L. R; REIS, M. J.; BORGES, D. G. Determinação do teor de etanol na gasolina dos postos de combustíveis do município de Passos (MG). Ciência et Praxis, v. 09, n. 18, 2016.

ABNT - ASSOCIAÇÃO BRASILEIRA DE NORMAS TÉCNICAS. ABNT-NBR - 13992: Gasolina Automotiva- Determinação do teor de álcool etílico anidro combustível (AEAC). Rio de Janeiro. Brasil. 1997.

CARVALHO, F. I. M.; DANTAS, F. H. A. Estudo da qualidade da gasolina tipo A e sua composição química empregando análise de componentes principais. Quim. Nova, v. 37, n. 1, p. 33-38, 2014.

DAHL, C. A. Measuring global gasoline and diesel Prince and income elasticities. Energy Policy, v. 41, p. 2-13, February 2012.

LODICE, P.; SENATORE, A.; LANGELLA, G.; AMORESANO, A. Effect of ethanol-gasoline blends on $\mathrm{CO}$ and $\mathrm{HC}$ emissions in last generation SI engines within the cold-start transient: An experimental investigation. Appl. Energy, v. 179, p.182-190, October 2016. 
MASUM, B.M.; MASJUKI, H. H.; KALAM, M. A.; RIZWANUL FATTAH, I. M.; PALASH, S. M.; ABEDIN, M. J. Effect of ethanol-gasoline blend on NOx emission in SI engine. Renewable and Sustainable Energy Reviews, v. 24, p. 209-222, August 2013.

MENDES, G.; BARBEIRA, P. J. S. Detection and quantification of adulterants in gasoline using distillation curves and multivariate methods. Fuel, v. 112, p. 163-171, October 2013.

NIVEN, R. K. Ethanol in gasoline: environmental impacts and sustainability review article. Renew. ust. Energ. Rev, v. 8, n. 6, p. 535-555, December 2005. 